apart from age, further be dependent on the availability of facilities, the preferences of patients and health care providers and on economic considerations.

\section{SAT0234 EVOLUTION IN THE USE OF NSAIDS BETWEEN 1991 AND 2000. IMPACT OF THE NEW MARKETED DRUGS}

${ }^{1} \mathrm{C}$ Llop, ${ }^{2} \mathrm{~S}$ Paredes. ${ }^{1}$ Pharmacy Unit, Catalonian Health Service, Tarragona; ${ }^{2}$ Rheumatology Service, Assistencial Service, Amposta, Spain

10.1136/annrheumdis-2001.870

Background Non-steroidal anti-inflammatory drugs (NSAIDs) are widely used drugs. In Catalonia (Spain), this group of drugs is the fourth most used group in the number of packages dispensed in recent years. Furthermore, new NSAIDs have recently become available on the Spanish pharmaceutical market.

Objectives To study the evolution in the use of NSAIDs in the province of Tarragona (Catalonia, Spain), with 450,000 inhabitants, during the period between 1991 and 2000. We also studied the commercial impact of the new marketed drugs in recent years.

Methods Data of all NSAIDs prescribed and dispensed in the Public Health System during the period of the study were obtained from the Catalonian Pharmacy Database. These data were converted into Defined Daily Doses (DDD) per 1,000 inhabitants per day (DHD), according the definition of the Nordisk Council of Medicine. Population of the province was obtained from the official census of various years.

Results The total amount of NSAIDs used has increased in these ten years from 24.12 to 42.54 DHD. Throughout the ten years period diclofenac, piroxicam, naproxen, ibuprofen, aceclofenac and indomethacin were the most used NSAIDs. The use of ibuprofen increased greatly and in the last year was the second most used drug in the group. Diclofenac and naproxen were used a lot throughout the period and even increased in the last years. Piroxicam and indomethacin decreased slightly over the period studied.

The use of new NSAIDs (dexketoprofen, nimesulide, celecoxib, lornoxicam and particularly meloxicam and rofecoxib) increased considerably. Rofecoxib was the fourth most used drug in the group in its first year on the market. New NSAIDs are more than 20\% of the total NSAIDs used in the year 2000. Since the new NSAIDs have become available, other minoritary drugs such as ketoprofen, flurbiprofen or tenoxicam have been used much less.

Conclusion Despite the considerable number of NSAIDs available in Spain, only ten represent almost 95\% of the total NSAIDs used in the year 2000. Concerns about a possible overprescription of these drugs are reflected in the increase of use between 1991 and 2000. Data from the last year show that more than 40 people out of every 1,000 daily use a NSAID. The increase in the use of ibuprofen is noticeable but the new NSAIDs have had a commercial impact that was both considerable and fast. We conclude that aggressive advertising by pharmaceutical companies greatly influences the use and the selection of these drugs.

\section{REFERENCES}

1 Brooks PM, Day RO. Non-steroidal anti-inflammatory drugs. Differences and similarities. N Engl J Med. 1991;324:1716-25

2 Llop C, Paredes S, Llor C. Criteria for selecting and using non-steroidal antiinflammatory drugs in primary health care. Fam Practice 2000;17:63-5

\section{SAT0235 DETERMINANTS OF PRODUCTIVITY COSTS IN AS. COMPARATIVE STUDY IN THE NETHERLANDS, FRANCE AND BELGIUM}

${ }^{1} \mathrm{AH}$ Boonen, ${ }^{1} \mathrm{D}$ Van der Heijde, ${ }^{2} \mathrm{H}$ Schouten, ${ }^{1} \mathrm{R}$ Landewe, ${ }^{3} \mathrm{~F}$ Guillemin, ${ }^{4} \mathrm{M}$ Dougados, ${ }^{5} \mathrm{~K}$ De Vlam, ${ }^{5} \mathrm{H}$ Mielants, ${ }^{1} \mathrm{~A}$ Spoorenberg, ${ }^{1} \mathrm{~S}$ Van der Linden. ${ }^{1}$ Rheumatology; ${ }^{2}$ Statistics, University Hospital Maastricht, Maastricht, The Netherlands; ${ }^{3}$ Rheumatology, Ecole Sante Publique, Nancy; ${ }^{4}$ Rheumatology, Hopital Cochin, Paris, France; ${ }^{5}$ Rheumatology, University Hospital Gent, Gent, BelgiumBackground

10.1136/annrheumdis-2001.871

Objectives To evaluate determinants of productivity costs in ankylosing spondylitis (AS) in three European countries.

Methods 216 consecutive prevalent AS out-patients started a 2 year longitudinal cost-of-illness study. AS-related health resource utilisation was collected by questionnaires every 2 months. Productivity costs were calculated by friction cost (FC) method and human capital (HC) approach. Cox proportional hazard analysis with costs as dependent variable was used to assess if ?country? was a determinant of productivity costs after controlling for age, gender, disease duration and time integrated disease activity (BASDAI:0-10; higher values indicating higher disease activity) if FC were the outcome or baseline physical function (BASFI:010; higher values indicating worse function) if $\mathrm{HC}$ costs were the outcome.

Results 209 patients completed follow-up. In the Netherlands $(\mathrm{NL}),(\mathrm{F})$ and (B) respectively, 70, 69 and 74\% of patients were male, mean age 46 (sd:12), 38 (sd: 12) and 42 (sd: 14) yr, mean disease duration 24 (sd:12), 14 (sd:9) and 13 (sd:10) yr and 34, 13 and 24\% had manual professions. 196 patients were in working age and 113 patients had a paid job.

\begin{tabular}{lll} 
Abstract SAT0235 & Table 1 & \\
\hline & Friction Costs $(\mathbf{n}=113)$ & Human Capital Costs $(\mathrm{n}=196)$ \\
& HR $[95 \% \mathrm{Cl}](\mathbf{p})$ & HR $[95 \% \mathrm{Cl}](\mathbf{p})$ \\
\hline Gender (female) & $\mathrm{ns}$ & $\mathrm{ns}$ \\
Age (HR/yr) & $1.08[1.04-1.2](0.0001)$ & $1.04[1.02-1.06](0.0001)$ \\
Disease duration & $\mathrm{ns}$ & $\mathrm{ns}$ \\
BASDAl (HR/point) & $1.2[1.1-1.3](0.04)$ & Not included as variable \\
BASFI (HR/point) & Not included as variable & $1.2[1.1-1.3](0.0001)$ \\
Manual profession & $\mathrm{ns}$ & $\mathrm{ns}$ \\
Country NL & $2.4[1.3-4.5](0.007)$ & $2.8[1.2-4.7](0.0007)$ \\
\hline
\end{tabular}

Conclusion In AS, productivity costs determined by FC and HC approach are significantly associated with the country studied. This finding has important consequences for the generalizability of health economic studies.

\section{SAT0236 A LONGITUDINAL EVALUATION OF THE EFFECT OF A DECISION-SUPPORT SYSTEM ON OUTCOME IN RHEUMATOID ARTHRITIS}

J Fransen, G Stucki, T Langenegger, M Seitz, BA Michel. SCQM C/O. Department of Rheumatology, University Hospital, Zurich, Switzerland

\subsection{6/annrheumdis-2001.872}

Background Management of patients with RA is challenging and poses specific problems. With the help of a decision-support system (Swiss Clinical Quality Management in RA) that gives the rheumatologist feedback on treatment outcomes, the treatment 